\title{
Antimethanogenic effects of nitrate supplementation in cattle: A meta-analysis
}

\author{
X. Y. Feng, ${ }^{1} \oplus$ J. Dijkstra, ${ }^{2} \oplus$ A. Bannink, ${ }^{3}$ S. van Gastelen, ${ }^{3} \oplus$ J. France, ${ }^{4} \oplus$ and E. Kebreab ${ }^{1 *} \oplus$ \\ ${ }^{1}$ Department of Animal Science, University of California, Davis 95616 \\ ${ }^{2}$ Animal Nutrition Group, Wageningen University \& Research, PO Box 338, $6700 \mathrm{AH}$, Wageningen, the Netherlands \\ ${ }^{3}$ Wageningen Livestock Research, Wageningen University \& Research, PO Box 338, $6700 \mathrm{AH}$, Wageningen, the Netherlands \\ ${ }^{4}$ Centre for Nutrition Modelling, Department of Animal Biosciences, University of Guelph, Guelph, Ontario, N1G 2W1, Canada
}

\begin{abstract}
Supplementing a diet with nitrate is regarded as an effective and promising methane $\left(\mathrm{CH}_{4}\right)$ mitigation strategy by competing with methanogens for available hydrogen through its reduction of ammonia in the rumen. Studies have shown major reductions in $\mathrm{CH}_{4}$ emissions with nitrate supplementation, but with large variation in response. The objective of this study was to quantitatively investigate the effect of dietary nitrate on enteric $\mathrm{CH}_{4}$ production and yield and evaluate the variables with high potential to explain the heterogeneity of between-study variability using meta-analytical models. A data set containing 56 treatments from 24 studies was developed to conduct a meta-analysis. Dry matter (DM) intake, nitrate dose (g/kg of DM), animal body weight, roughage proportion of diet, dietary crude protein and neutral detergent fiber content, $\mathrm{CH}_{4}$ measurement technique, and type of cattle (beef or dairy) were considered as explanatory variables. Average DM intake and $\mathrm{CH}_{4}$ production for dairy cows $(16.2 \pm 2.93$ $\mathrm{kg} / \mathrm{d} ; 311 \pm 58.8 \mathrm{~g} / \mathrm{d}$ ) were much higher than for beef cattle $(8.1 \pm 1.57 \mathrm{~kg} / \mathrm{d} ; 146 \pm 50.9 \mathrm{~g} / \mathrm{d})$. Therefore, a relative mean difference was calculated and used to conduct random-effect and mixed-effect model analysis to eliminate the large variations between types of animal due to intake. The final mixed-effect model for $\mathrm{CH}_{4}$ production (g of $\mathrm{CH}_{4} / \mathrm{d}$ ) had 3 explanatory variables and included nitrate dose, type of cattle, and DM intake. The final mixed-effect model for $\mathrm{CH}_{4}$ yield ( $\mathrm{g}$ of $\mathrm{CH}_{4} / \mathrm{kg}$ of DM intake) had 2 explanatory variables and included nitrate dose and type of cattle. Nitrate effect sizes on $\mathrm{CH}_{4}$ production (dairy: $-20.4 \pm 1.89 \%$; beef: $-10.1 \pm 1.52 \%$ ) and yield (dairy: $-15.5 \pm 1.15 \%$; beef: $-8.95 \pm 1.764 \%$ ) were significantly different between the 2 types of cattle. When data from slow-release nitrate sources were removed from the analysis, there was
\end{abstract}

Received March 16, 2020.

Accepted July 13, 2020.

*Corresponding author: ekebreab@ucdavis.edu no significant difference in type of cattle anymore for $\mathrm{CH}_{4}$ production and yield. Nitrate dose enhanced the mitigating effect of nitrate on $\mathrm{CH}_{4}$ production and yield by $0.911 \pm 0.1407 \%$ and $0.728 \pm 0.2034 \%$, respectively, for every $1 \mathrm{~g} / \mathrm{kg}$ of DM increase from its mean dietary inclusion $(16.7 \mathrm{~g} / \mathrm{kg}$ of DM). An increase of $1 \mathrm{~kg}$ of $\mathrm{DM} / \mathrm{d}$ in $\mathrm{DM}$ intake from its mean dietary intake (11.1 $\mathrm{kg}$ of $\mathrm{DM} / \mathrm{d}$ ) decreased the effect of nitrate on $\mathrm{CH}_{4}$ production by $0.691 \pm 0.2944 \%$. Overall, this metaanalysis demonstrated that nitrate supplementation reduces $\mathrm{CH}_{4}$ production and yield in a dose-dependent manner, and that elevated DM intake decreases the effect of nitrate supplementation on $\mathrm{CH}_{4}$ production. Furthermore, the stronger antimethanogenic effect on $\mathrm{CH}_{4}$ production and yield in dairy cows than in beef steers could be related to use of slow-release nitrate in beef cattle.

Key words: beef, dairy, nitrate, meta-analysis, methane

\section{INTRODUCTION}

Livestock production makes up $14.5 \%$ of global greenhouse gas emissions (Gerber et al., 2013), with enteric methane $\left(\mathrm{CH}_{4}\right)$ production contributing about $2.1 \mathrm{Gt}$ $\mathrm{CO}_{2}$ equivalent in 2010 (Smith et al., 2014). Methane emissions from enteric fermentation represented $39 \%$ of all greenhouse gas emissions from the livestock sector (Gerber et al., 2013). In addition, $\mathrm{CH}_{4}$ can be considered an energy loss of around $6 \%$ of ingested dietary energy (Niu et al., 2018). Therefore mitigation of enteric $\mathrm{CH}_{4}$ emissions will reduce the environmental impact of livestock if total number of animals remains constant.

Several feed additives that reduce enteric $\mathrm{CH}_{4}$ emissions are increasingly being investigated worldwide (Hristov et al., 2013). Nitrate $\left(\mathrm{NO}_{3}^{-}\right)$is an inorganic anion and acts as an alternative hydrogen sink in the rumen competing with methanogens for hydrogen utilization. The reduction of nitrate to nitrite $\left(\mathrm{NO}_{3}{ }^{-}+\right.$ $\mathrm{H}_{2} \rightarrow \mathrm{NO}_{2}{ }^{-}+\mathrm{H}_{2} \mathrm{O}$; Gibbs free energy, $\Delta \mathrm{G}=-130$ $\mathrm{kJ} / \mathrm{mol}$ of hydrogen; Ungerfeld and Kohn, 2006) and the subsequent reduction of nitrite to ammonia $\left(\mathrm{NO}_{2}{ }^{-}\right.$ 
$+3 \mathrm{H}_{2}+2 \mathrm{H}^{+} \rightarrow \mathrm{NH}_{4}^{+}+2 \mathrm{H}_{2} \mathrm{O} ; \Delta \mathrm{G}=-124 \mathrm{~kJ} / \mathrm{mol}$ of hydrogen; Ungerfeld and Kohn, 2006) yields more energy than the reduction of $\mathrm{CO}_{2}$ to $\mathrm{CH}_{4}\left(\mathrm{CO}_{2}+4 \mathrm{H}_{2}\right.$ $\rightarrow \mathrm{CH}_{4}+2 \mathrm{H}_{2} \mathrm{O} ; \Delta \mathrm{G}=-16.9 \mathrm{~kJ} / \mathrm{mol}$ of hydrogen; Ungerfeld and Kohn, 2006). Thus, nitrate reduction is highly competitive with methanogenesis because it leads the utilization of hydrogen away from reduction of $\mathrm{CO}_{2}$ to $\mathrm{CH}_{4}$, which becomes emitted as enteric $\mathrm{CH}_{4}$ (Olijhoek et al., 2016).

Several in vivo studies have investigated the effects of nitrate as a $\mathrm{CH}_{4}$ mitigation strategy in different types of ruminants such as beef steers (Hulshof et al., 2012; Troy et al., 2015; Alemu et al., 2019), dairy cows (Veneman et al., 2015; Klop et al., 2016; Meller et al., 2019), sheep (Sar et al., 2004; van Zijderveld et al., 2010), and goats (Zhang et al., 2019). In a meta-analysis, Lee and Beauchemin (2014) demonstrated that nitrate is a viable candidate feed additive that could be used to mitigate enteric $\mathrm{CH}_{4}$ emissions in ruminants. In a more recent analysis, van Gastelen et al. (2019) demonstrated that $\mathrm{CH}_{4}$ production was indeed consistently decreased when feeding nitrate to different types of ruminant. The same average proportion of the theoretical $\mathrm{CH}_{4}$ production reduction potential of nitrate was reached for dairy cattle $(72 \%)$, beef cattle $(72 \%)$, and sheep (74\%). However, both analyses did not investigate possible sources of variability in $\mathrm{CH}_{4}$ mitigation effect of nitrate other than nitrate dose (Lee and Beauchemin, 2014) and ruminant type (van Gastelen et al., 2019). Some studies reported $\mathrm{CH}_{4}$ reduction through nitrate supplementation of up to $30 \%$ (e.g., Newbold et al., 2014), whereas others found an increase of $\mathrm{CH}_{4}$ production of 3.8\% (Tomkins et al., 2018).

The objective of this study was to collate data on nitrate supplementation for $\mathrm{CH}_{4}$ mitigation and quantitatively evaluate the effects of dietary nitrate for enteric $\mathrm{CH}_{4}$ production and yield in dairy and beef cattle. In the present meta-analysis, we hypothesize that, in addition to nitrate dose, DMI, nutrient composition of the diet, BW, measurement techniques [respiratory chamber, GreenFeed, and sulfur hexafluoride tracer $\left.\left(\mathbf{S F}_{\mathbf{6}}\right)\right]$ for $\mathrm{CH}_{4}$ emissions, and type of cattle (dairy or beef) may explain a considerable proportion of the variability in $\mathrm{CH}_{4}$ mitigation effect of nitrate. Therefore, this study quantitatively analyzed explanatory variables to account for the heterogeneity in $\mathrm{CH}_{4}$ mitigation potential of nitrate using a meta-analytic approach.

\section{MATERIALS AND METHODS}

\section{Data Sources}

A literature search was conducted using several sources including the Web of Science (Thomson Reuters
Science, New York, NY), Scopus (Elsevier, Amsterdam, the Netherlands), and Google Scholar online databases with all possible combinations of the key words "feed additives," "nitrate," "methane" (including variants of " $\mathrm{CH}_{4}$ " and "greenhouse gas"), "cattle" (including variants of "dairy," "beef," "steer," "cows," and "ruminants"). The period of the study covered from 1970 to 2020. The search resulted in 45 references related to the effects of nitrate on enteric $\mathrm{CH}_{4}$ emissions in cattle. All articles were scrutinized by reading the abstracts, experimental design, and results carefully. To be included in the database, the studies were required to meet the following criteria: (1) have a control treatment group that did not receive supplementary nitrate; (2) trials conducted in vivo using cattle; (3) measured (i.e., not estimated) $\mathrm{CH}_{4}$ emissions with standard deviation, standard error, or other relative data that can be used to calculate the standard error (e.g., least significant difference); (4) and other required variables described such as animal characteristics, DMI, dietary composition, and BW. Of the 45 articles, 24 articles and 56 treatment means were selected in the final database after removal of articles for various reasons (2 were general summaries; 3 had abstracts only; 3 investigated the mitigation effect on $\mathrm{CH}_{4}$ of a mixture of nitrate and other feed additives, which did not contain a contrast with nitrate treatment group; 5 did not report $\mathrm{CH}_{4}$ emissions; 5 did not provide sufficient information regarding dietary composition; and 3 were duplicates of references already included in the database). One treatment from Lee et al. (2017b) was excluded based on the prescreening of $\mathrm{CH}_{4}$ reduction rate for extreme outliers that exceeded 1.5 interquartile ranges (IQR) below the first quartile (first quartile $-1.5 \mathrm{IQR}$ ) or above the third quartile (third quartile + 1.5 IQR) (Upton and Cook, 1996). A PRISMA statement according to Liberati et al. (2009) has been provided (Supplemental Figure S1, https://doi.org/10.3168/jds.2020-18541). Of the 56 treatment means, 35 treatment means related to beef cattle (Hulshof et al., 2012; Newbold et al., 2014; Lee et al., 2015; Troy et al., 2015; Henry, 2017; Lee et al., 2017a,b; Capelari, 2018; Duthie et al., 2018; Tomkins et al., 2018; Alemu et al., 2019; Granja-Salcedo et al., 2019; Rebelo et al., 2019; Villar et al., 2020) and 21 treatment means related to dairy cattle (van Zijderveld et al., 2011b; Guyader et al., 2015a,b; Veneman et al., 2015; Klop et al., 2016; Olijhoek et al., 2016; van Wyngaard et al., 2018; Wang et al., 2018; Meller et al., 2019; van Wyngaard et al., 2019; Table 1). All beef cattle in the selected studies were steers except in Lee et al. (2015), which were beef heifers. Studies in 2 articles used beef cattle at the backgrounding phase (Lee et al., 2017a; Alemu et al., 2019), studies in 4 articles used cattle in the growing stage (Lee et 
al., 2015; Capelari, 2018; Duthie et al., 2018; Rebelo et al., 2019), studies in 4 articles used cattle at the finishing phase (Troy et al., 2015; Lee et al., 2017b; Granja-Salcedo et al., 2019; Villar et al., 2020), 1 study used 2-yr-old steers (Tomkins et al., 2018), whereas 3 articles did not report type of beef cattle (Hulshof et al., 2012; Newbold et al., 2014; Henry, 2017). Diets included grazing pasture in 4 studies (van Wyngaard et al., 2018; Granja-Salcedo et al., 2019; van Wyngaard et al., 2019), or feed delivered to cattle in housed pens and stalls (all others; 52 studies). Nitrate was provided in various forms. It was either mixed with concentrates and provided in pelleted form (Guyader et al., 2015a,b; van Wyngaard et al., 2018; van Wyngaard et al., 2019), mixed with molasses as a carrier (Henry, 2017; Tomkins et al., 2018), offered as encapsulated nitrate (Lee et al., 2015; Henry, 2017; Lee et al., 2017a,b; Alemu et al., 2019; Granja-Salcedo et al., 2019; Rebelo et al., 2019), or directly delivered with the diets (all others). In Lee et al. (2017a), 2 treatments had encapsulated nitrate, and 1 treatment used un-encapsulated nitrate; in Lee et al. (2017b), 1 treatment had encapsulated nitrate, and 1 treatment had un-encapsulated nitrate. The respiration chamber (16 studies; 9 for beef cattle and 7 for dairy cattle), GreenFeed (2 studies; 1 for beef cattle and 1 for dairy cattle), and $\mathrm{SF}_{6}$ tracer (6 studies; 4 for beef cattle and 2 for dairy cattle) techniques were used to measure $\mathrm{CH}_{4}$ emissions in the selected studies. If the control diet contained nitrate (e.g., nitrate in grass silage), the treatment level of nitrate was assumed to be the difference between the actual nitrate level and the control nitrate level. Data used in the analysis are provided in Supplemental Table S1 (https://doi.org/10 .3168/jds.2020-18541).

Methane production was generally reported in grams per day and $\mathrm{CH}_{4}$ yield in grams per kilogram of DMI. If the values were reported in liters or moles per day, they were converted to grams per day assuming a molar gas volume of $22.4 \mathrm{~L}$ and a molar weight of $16.0 \mathrm{~g}$. If only $\mathrm{CH}_{4}$ production or $\mathrm{CH}_{4}$ yield was reported, the other unit of $\mathrm{CH}_{4}$ emissions was calculated using the equation $\mathrm{CH}_{4}$ yield (in $\mathrm{g} / \mathrm{kg}$ of $\mathrm{DMI}$ ) $=\mathrm{CH}_{4}$ production (in $\mathrm{g} / \mathrm{d}$ )/DMI (in kg/d). Summary statistics of feed intake, nutrient composition of the experimental diets, nitrate supplement, and $\mathrm{CH}_{4}$ emissions are given in Table 1 .

\section{Model Development and Selection}

Meta-analysis is a statistical methodology that combines quantitative findings from various studies for the main purpose of synthesizing the evidence based on the available sources (Schwarzer et al., 2015). To prepare for the meta-analysis, effect size estimates and corresponding sampling variances were obtained using the

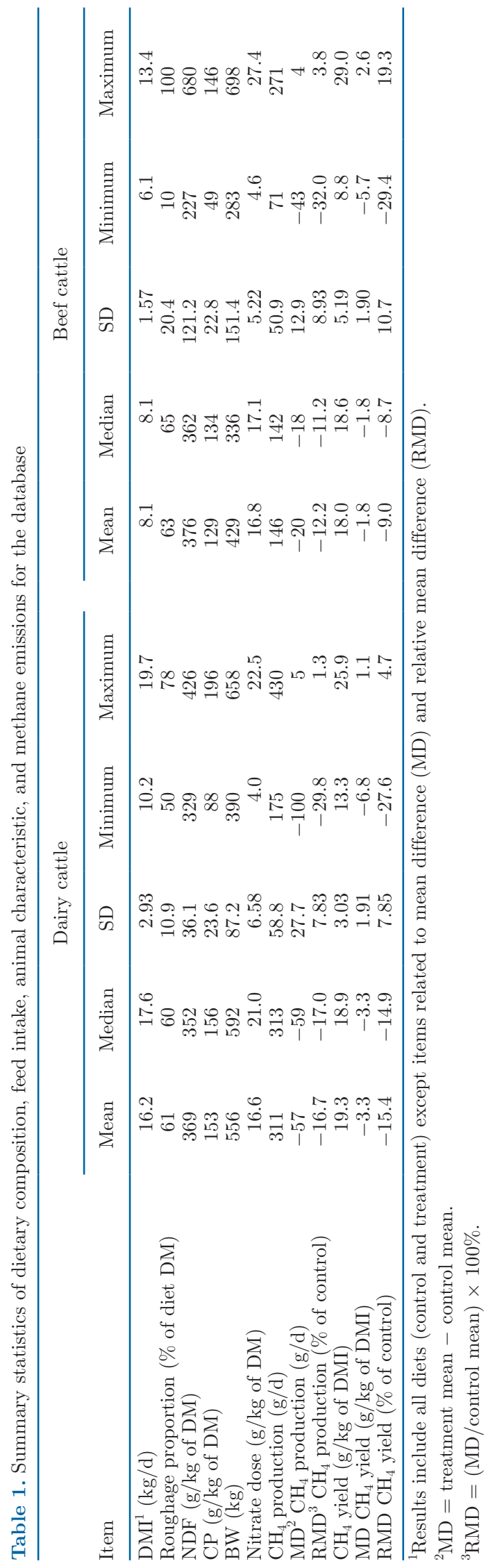


"metafor" (version 2.1-0) and "robumeta" (version 2.1) packages in $\mathrm{R}$ (version 3.6.1, R Foundation for Statistical Computing, Vienna, Austria). The mean difference (MD) and standardized mean difference (SMD) were used to measure the continuous response variables of $\mathrm{CH}_{4}$ production and yield. The MD was calculated as nitrate treatment mean minus control treatment mean and each study was weighted by its corresponding sample variation (Viechtbauer, 2010). The SMD was expressed as dividing MD by the pooled standard deviation of the 2 groups and used to construct forest plots of response variables. The relative mean difference $(\mathbf{R M D} ; \mathrm{RMD}=\mathrm{MD} /$ control treatment mean $\times$ $100 \%$ ), which is a dimensionless variable, was calculated for further analyses to eliminate the large variations and different measuring scales of DMI and $\mathrm{CH}_{4}$ production from study to study.

General meta-regression methods require independence of effect sizes. However, multiple nitrate treatment groups may share a common control treatment group in some of the studies used in our database. To deal with the unknown correlations among these nonindependent effect sizes, a robust variance estimation (RVE) method (Tipton, 2015) was used to conduct the meta-analysis. Studies selected in the meta-analysis were not identical in methods and sample characteristics, which may introduce variance of the true effect sizes. Therefore, RVE random-effects and RVE mixedeffects models were fitted to estimate between-study variability (heterogeneity) that was assumed to be purely random (Tanner-Smith et al., 2016; Dijkstra et al., 2018) using the "robu" function in the "robumeta" package (version 2.1) in $\mathrm{R}$ (version 3.6.1). The RVE random-effects model was written as

$$
y_{i j}=\beta_{0}+\mu_{j}+e_{i j}
$$

where for $i=1, \ldots, k_{j}$ effect sizes, and $j=1, \ldots, m$ studies, $y_{i j}$ is the $i$ th effect size of the $j$ th study, $\beta_{0}$ is the average true effect, $\mu_{j}$ is the random effect at study level where $\mu_{j} \sim N\left(\mathbf{0}, \tau^{2}\right)$ and $\tau^{2}$ is the between-study variance component, and $e_{i j}$ is the residual for $i$ th effect size in the $j$ th study where $e_{i j} \sim N\left(\mathbf{0}, s_{i}{ }^{2}\right)$ and $s_{i}{ }^{2}$ is the error variance component. The between-study variance $\tau^{2}$, which reflects the amount of true heterogeneity in the correlated effects meta-regression model, is calculated using the method-of-moments estimator (Hedges et al., 2010). The $I^{2}$ measures the inconsistency in metaanalysis and is defined as the ratio of true heterogeneity to the total variability across the observed effect sizes. $I^{2}$ values of $25 \%, 50 \%$, and $75 \%$ are considered as low, moderate, and high heterogeneity, respectively (Higgins et al., 2003). For the RVE model, $I^{2}$ was calculated as

$$
I^{2}=\frac{Q_{E}-d f}{Q_{E}} \times 100 \%,
$$

where $Q_{E}$ is the weighted residual sum of squares or Cochran's heterogeneity, and $d f$ is the degrees of freedom (Higgins et al., 2003). To examine effect size moderators and reduce heterogeneity, the RVE random-effects models can be extended to RVE mixed-effects models, which include variables with the potential to account for some of the observed variability. The RVE mixedeffects model was written as

$$
y_{i j}=\beta_{0}+\mu_{j}+\mathbf{X}_{i j} \boldsymbol{\beta}+e_{i j},
$$

where $\beta_{0}, \mu_{j}$, and $e_{i j}$ are as defined above, $\boldsymbol{\beta}=\left(\beta_{1}, \ldots\right.$ $\left.\beta_{p}\right)$ is a vector of unknown regression coefficients based on weighted least-squares estimates, and $\mathbf{X}_{i j}$ is a vector of continuous or binary explanatory variables. The inverse variance weights of "correlated effects" used in RVE models were estimated following a method provided by Hedges et al. (2010):

$$
w_{i j}=\frac{1}{k_{j}\left(v_{. j}+\tau^{2}\right)},
$$

where $w_{i j}$ is the $i$ th inverse variance weight in the $j$ th study, $k_{j}$ is the number of effect sizes for each study $j, v_{. j}$ is the mean of within-study sampling variances $\left(v_{i j}\right)$ for the $k_{j}$ effect sizes in the $j$ th study, and $\tau^{2}$ is the betweenstudy variance component as defined previously, which describes the residual of heterogeneity that is not explained by the involved variables.

The primary response variables were the means of $\mathrm{CH}_{4}$ emissions in the control and nitrate treatment groups. Dry matter intake, BW, roughage proportion in the diet, dietary $\mathrm{CP}$ and NDF content $(\mathrm{g} / \mathrm{kg}$ of $\mathrm{DM})$, and nitrate dose $(\mathrm{g} / \mathrm{kg}$ of $\mathrm{DM})$ were selected as potential continuous explanatory variables. Type of cattle (dairy or beef) and $\mathrm{CH}_{4}$ measurement technique (respiratory chamber, GreenFeed, or $\mathrm{SF}_{6}$ tracer) were used as categorical variables. Therefore, the vector $\boldsymbol{\beta}$ can be explained as the differences in true effect sizes according to each unit changing in the continuous variables or between the 2 types of animals and different measurement techniques. The RVE models were first fitted with each individual variable, and subsequently including one or more variables with the "robu" function in a stepwise manner until all explanatory variables were involved to construct full mixed-effect models (Dijkstra et al., 2018). Only the variables that showed significant effects $(P<0.10)$ were retained until the final model 
was selected. Multicollinearity was investigated to examine the correlations among variables using the "cor" function in $\mathrm{R}$ (version 3.6.1), and highly correlated variables $(|\mathrm{r}|>0.50)$ were not analyzed in the same model [e.g., DMI and CP $(|\mathrm{r}|=0.60)$, and $\mathrm{CP}$ and NDF $(|\mathrm{r}|=0.55)]$. All explanatory variables (except for type of cattle and $\mathrm{CH}_{4}$ measurement technique) were first centered on their means. Potential variables such as GE content, ash content, fat content, and OM digestibility were also considered in data collection; however, due to the lack of information in most of the publications, they were not included in this analysis.

\section{RESULTS AND DISCUSSION}

The meta-analysis conducted in the current study aimed to evaluate the effects of nitrate as a feed additive to reduce $\mathrm{CH}_{4}$ production and yield in dairy and beef cattle. The mean daily DMI and $\mathrm{CH}_{4}$ production of dairy cows $(16.2 \pm 2.93 \mathrm{~kg} / \mathrm{d} ; 311 \pm 58.8 \mathrm{~g} / \mathrm{d}$, respectively) were greater than those of beef steers (8.1 $\pm 1.57 \mathrm{~kg} / \mathrm{d} ; 146 \pm 50.9 \mathrm{~g} / \mathrm{d}$ ), whereas the means of supplemented nitrate dose were not different between dairy $(16.6 \pm 6.58 \mathrm{~g} / \mathrm{kg}$ of DM) and beef cattle $(16.8 \pm$ $5.22 \mathrm{~g} / \mathrm{kg}$ of DM). On average, the effects of the mean nitrate dose resulted in greater RMD in $\mathrm{CH}_{4}$ production and yield for dairy cows $(-16.7 \pm 7.83 \%$ and -15.4 $\pm 7.85 \%$, respectively) than for beef steers $(-12.2 \pm$ $8.93 \%$ and $-9.0 \pm 10.75 \%$, respectively). Forest plots generated with SMD for $\mathrm{CH}_{4}$ production (Figure 1) and $\mathrm{CH}_{4}$ yield (Figure 2) indicate that nitrate mostly had an antimethanogenic effect, but that the size of effect varies across studies. Given the overall effect size that accounted for sampling variation within and between studies, at a mean nitrate dose of $16.7 \mathrm{~g} / \mathrm{kg}$ of DM, the overall $\mathrm{CH}_{4}$ production $(P<0.001)$ and $\mathrm{CH}_{4}$ yield $(P<0.001)$ were reduced by $13.9 \pm 1.17 \%$ and $11.4 \pm$ $1.36 \%$, respectively, based on the random-effect RVE models (Table 2). Several other feed additives have also been shown to reduce $\mathrm{CH}_{4}$ emissions but mostly at a lower effectiveness. For example, Appuhamy et al. (2013) reported monensin reduced $\mathrm{CH}_{4}$ production by $5.6 \%$ for dairy cows and $4.6 \%$ for beef steers. Eugène et al. (2008) investigated lipid supplementation and reported it reduced $\mathrm{CH}_{4}$ production by $9.0 \%$ in lactating dairy cows. Van Zijderveld et al. (2011a) observed a $10 \%$ decrease in $\mathrm{CH}_{4}$ emissions by supplementing mixed additives of lauric acid, myristic acid, and linseed oil in dairy cattle. However, specific inhibitors of methanogenesis can cause a larger extent of decrease in methane production, such as Bovaer (formerly known as 3-nitroxypropanol), which showed $39 \%$ and $22 \%$ inhibition of $\mathrm{CH}_{4}$ production in dairy and beef cattle, respectively (Dijkstra et al., 2018).
The RVE random-effect models showed that a large proportion of the total variability in nitrate effects on $\mathrm{CH}_{4}$ production $\left(I^{2}=99.99 \%\right)$ and $\mathrm{CH}_{4}$ yield $\left(I^{2}=\right.$ $99.99 \%$ ) was attributable to heterogeneity. Potential explanatory variables were included individually to conduct mixed-effect RVE models to further understand and improve the random-effect models (Table 2; 1 explanatory variable). The effectiveness of nitrate in reducing $\mathrm{CH}_{4}$ production was positively associated with nitrate dose $(P<0.001)$. A $1 \mathrm{~g} / \mathrm{kg}$ of DM increase in nitrate dose from its mean $(16.7 \mathrm{~g} / \mathrm{kg}$ of DM) enhanced the nitrate antimethanogenic effect on $\mathrm{CH}_{4}$ production by $0.904 \pm 0.1461 \%$. For RMD in $\mathrm{CH}_{4}$ production, the categorical variable measurement technique $(P=$ $0.101)$ and the continuous variables $\mathrm{BW}(P=0.289)$, NDF content $(P=0.783), \mathrm{CP}$ content $(P=0.714)$, roughage proportion of diet $(P=0.796)$, and DMI $(P$ $=0.259)$ were not significant, whereas type of cattle $(P=0.055)$ tended to be significant. For RMD in $\mathrm{CH}_{4}$ yield, BW $(P=0.170)$, NDF content $(P=0.662)$, CP content $(P=0.997)$, roughage proportion of $\operatorname{diet}(P=$ $0.774)$, and measurement technique $(P=0.120)$ were not significant either, whereas type of cattle $(P=0.014)$ and nitrate dose $(P=0.002)$ were significant and DMI tended to be significant $(P=0.072)$. A $1 \mathrm{~g} / \mathrm{kg}$ of DM increase in nitrate dose from its mean $(16.7 \mathrm{~g} / \mathrm{kg}$ of DM) resulted in $0.719 \pm 0.1994 \%$ decline in $\mathrm{CH}_{4}$ yield (Table 2 , model I). The heterogeneity was reduced by including one explanatory variable for both $\mathrm{CH}_{4}$ production $\left(\tau^{2}=60.6\right.$ vs. 30.4$)$ and $\mathrm{CH}_{4}$ yield $\left(\tau^{2}=52.8\right.$ vs. 30.7 ; Table 2). These results agree with Lee and Beauchemin (2014) who reported a linear reduction in $\mathrm{CH}_{4}$ yield with increasing nitrate dose. Nitrate mitigation effects on $\mathrm{CH}_{4}$ yield in dairy and beef cattle were $-15.4 \pm$ $1.71 \%$ and $-9.00 \pm 1.817 \%$, respectively, which were significantly different from each other (Table 2; model II). This indicates that nitrate has a stronger $\mathrm{CH}_{4}$ yield mitigating effect for dairy cattle than for beef cattle, and that a higher nitrate dose is required for beef cattle to obtain the same $\mathrm{CH}_{4}$ yield mitigation compared with dairy cattle. The efficacy of nitrate utilization appears to be greater and the potential of the nitrate inhibitory effect seems enhanced in dairy cattle, perhaps through a more complete nitrate reduction. Another explanation for the greater mitigating effect in dairy cattle compared with beef cattle is related to the form in which nitrate is supplied. Nitrate provided in encapsulated form was given to only beef cattle in our database. Slow-release nitrate might have a lower capacity to decrease $\mathrm{CH}_{4}$ emissions because it may have been washed out of the rumen before the nitrate is released to be reduced to ammonia, contributing to differences in type of cattle. The effects of individual type of cattle on $\mathrm{CH}_{4}$ production $(P=0.205$; data not shown $)$ and yield $(P$ 
$=0.164$; data not shown) were no longer significant after removing all experiments with slow-release nitrate (15 treatments from 7 articles) from the meta-analysis, which indicated that the use of slow-release nitrate in beef cattle may explain the type of cattle effect in $\mathrm{CH}_{4}$ emissions. In comparison with the mixed-effect model (1 explanatory variable) that did contain slow-release nitrate, the model without slow-release nitrate had a greater overall effect size $\left(\mathrm{CH}_{4}\right.$ production, $-15.0 \pm$ $1.12 \% ; \mathrm{CH}_{4}$ yield, $\left.-13.2 \pm 1.46 \%\right)$ and a slightly smaller slope value $\left(\mathrm{CH}_{4}\right.$ production, $-0.883 \pm 0.1564 \% ; \mathrm{CH}_{4}$ yield, $-0.687 \pm 0.2014 \%$ ). Mixed-effect models with 2 or more explanatory variables based on data excluding slow-release urea are presented in Supplemental Table S2 (https://doi.org/10.3168/jds.2020-18541).

Upon adjusting the RVE mixed-effect model to include 2 explanatory variables, nitrate dose and type of cattle were selected for $\mathrm{CH}_{4}$ production and yield (Table $2 ; 2$ as explanatory variables; model I). When adjusted for the effect of nitrate dose, the $\mathrm{CH}_{4}$ production and yield mitigating effect of nitrate was larger in dairy cattle $(16.9 \pm 0.97 \%$ and $15.5 \pm 1.15 \%$, respectively $)$ than in beef cattle $(12.2 \pm 1.33 \%$ and $8.95 \pm 1.764 \%$, respectively). A $1 \mathrm{~g} / \mathrm{kg}$ increase in nitrate dose from

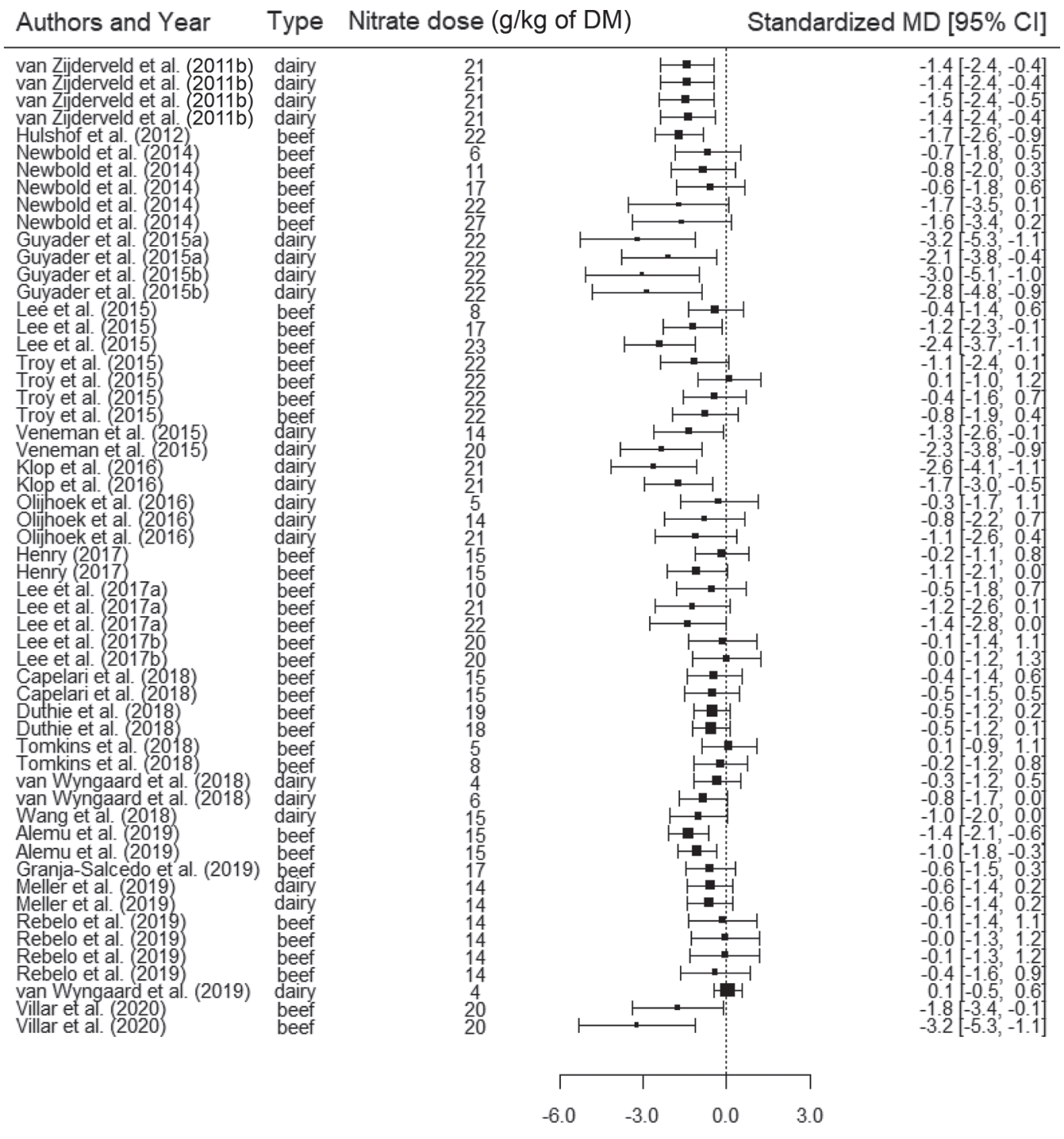

Standardized Mean Difference (Methane Production, g/d)

Figure 1. Forest plot showing nitrate dose $(\mathrm{g} / \mathrm{kg}$ of $\mathrm{DM})$ and standardized mean difference (MD) in $\mathrm{CH}_{4}$ production ( $\left.\mathrm{g} / \mathrm{d}\right)$ and its $95 \% \mathrm{CI}$ for beef and dairy cattle from selected studies. The dotted line represents a reference of 0 standardized MD. The black squares represent the power of its corresponding studies. (Note: A larger box indicates a greater sample size and a smaller CI). 


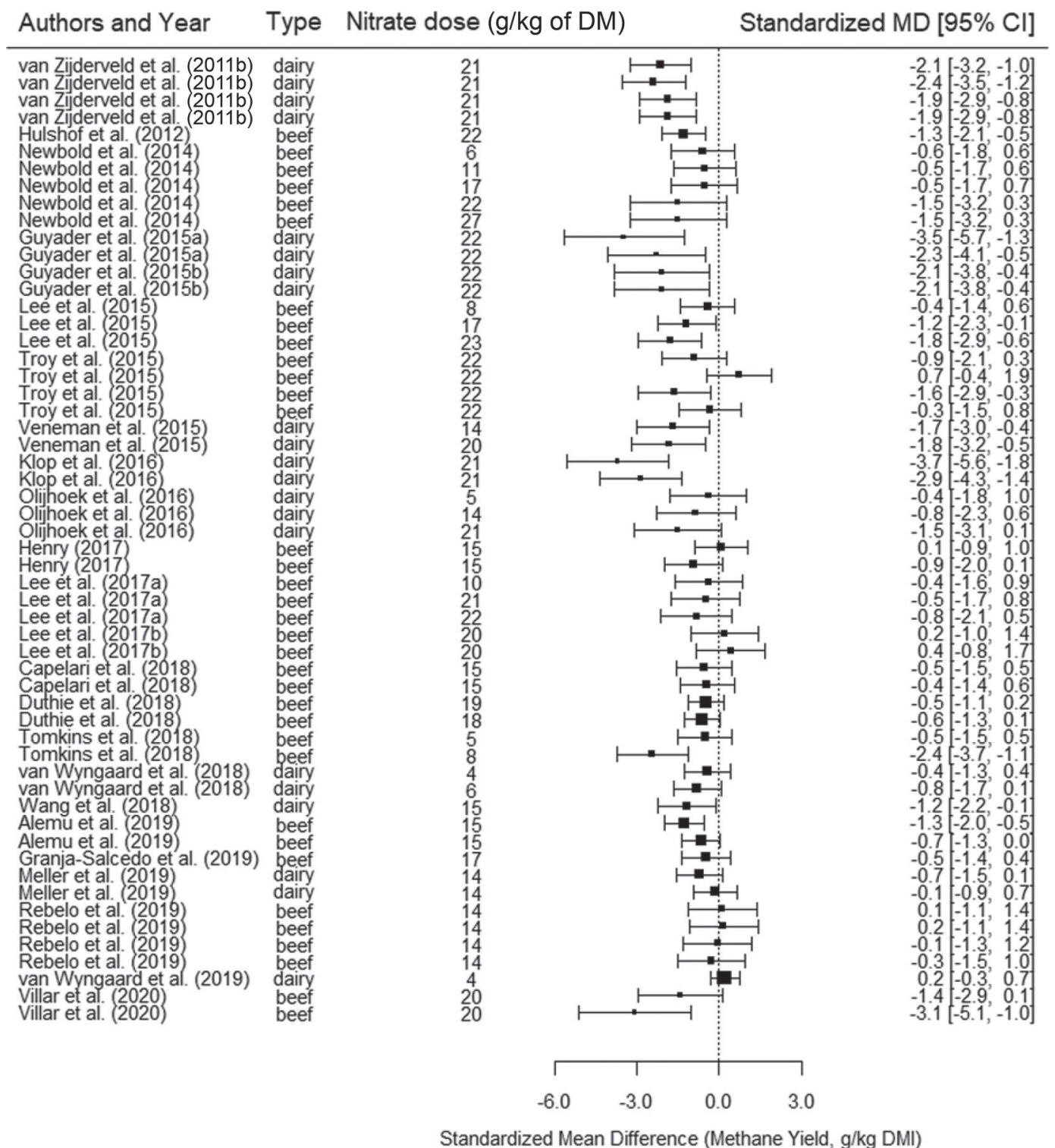

Figure 2. Forest plot showing nitrate dose (g/kg of DM) and standardized mean difference (MD) in $\mathrm{CH}_{4}$ yield $(\mathrm{g} / \mathrm{kg}$ of $\mathrm{DMI})$ and its $95 \%$ CI for beef and dairy cattle from selected studies. The dotted line represents a reference of 0 standardized MD. The black squares represent the power of its corresponding studies. (Note: A larger box indicates a greater sample size and a smaller CI).

its mean enhanced the mitigating effect of nitrate on $\mathrm{CH}_{4}$ production by $0.910 \pm 0.1481 \%$ and yield by 0.728 $\pm 0.2034 \%$. Compared with the single explanatory variable mixed-effect model, the mixed-effect model containing both type of cattle and nitrate dose further reduced the heterogeneity for $\mathrm{CH}_{4}$ production and yield $\left(\tau^{2}=30.4\right.$ vs. 30.1 , and 30.7 vs. 30.1 , respectively $)$.

No further variables were found to be significant in the final step for predicting $\mathrm{CH}_{4}$ yield; therefore, the final mixed-effect model for RMD in $\mathrm{CH}_{4}$ yield (Table 2 ) included type of cattle and nitrate dose. For $\mathrm{CH}_{4}$ production, the $\tau^{2}$ further decreased from the mixed- effect model with 2 explanatory variables $\left(\tau^{2}=30.1\right)$ to 3 explanatory variables $\left[\tau^{2}=26.3\right.$ (model I) and $\tau^{2}$ $=27.8$ (model II)] (Table 2). In model I of the mixedeffects model with 3 explanatory variables for $\mathrm{CH}_{4}$ production, after adjusting for type of cattle and DMI in the mixed-effect model, nitrate-induced $\mathrm{CH}_{4}$ mitigation was $-0.911 \pm 0.1407 \%(P<0.001)$ per $1 \mathrm{~g} / \mathrm{kg}$ of $\mathrm{DM}$ increase in nitrate dose from its mean $(16.7 \mathrm{~g} / \mathrm{kg}$ of DM; Table 2), which is similar to the effect of nitrate dose observed in the individual and 2 explanatory variables mixed-effect models. After centering nitrate dose on its mean, an increase in DMI decreased $(P=0.033)$ the 
Feng et al.: ANTIMETHANOGENIC EFFECT OF NITRATE IN CATTLE

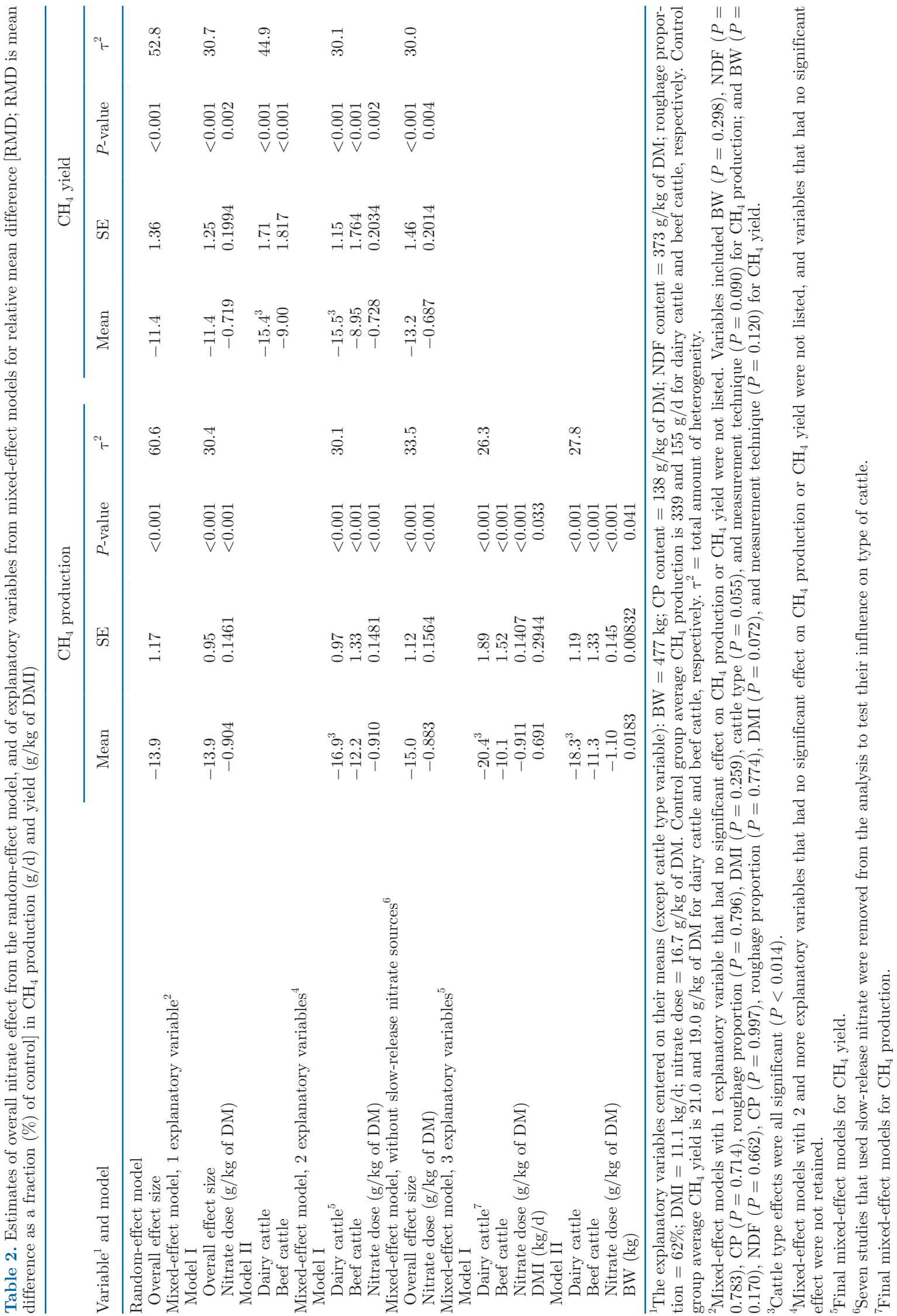


$\mathrm{CH}_{4}$ production-mitigating effect of nitrate by 0.691 $\pm 0.2944 \%$ for every $1 \mathrm{~kg} / \mathrm{d}$ increase in DMI from its mean $(11.1 \mathrm{~kg} / \mathrm{d})$. At mean DMI, the antimethanogenic effect of nitrate was stronger $(P=0.005)$ in dairy cows $(-20.4 \pm 1.89 \% ; P<0.001)$ compared with beef cattle $(-10.1 \pm 1.52 \% ; P<0.001)$.

Similarly, at mean nitrate dose $(16.7 \mathrm{~g} / \mathrm{kg}$ of $\mathrm{DM})$ and BW (477 kg/cow) in the mixed-effect model II with 3 explanatory variables, nitrate mitigated $\mathrm{CH}_{4}$ production to a greater extent $(P=0.001)$ in dairy cows $(-18.3 \pm 1.19 \% ; P<0.001)$ than in beef cattle $(-11.3 \pm 1.33 \% ; P<0.001)$. The greater efficacy in dairy cattle may be related to the use of slow-release nitrate only in beef cattle diets, and furthermore to the differences in the levels of feed intake (dairy: 16.2 $\mathrm{kg}$ of $\mathrm{DM} / \mathrm{d}$, beef: $8.1 \mathrm{~kg}$ of $\mathrm{DM} / \mathrm{d}$; Table 1). Higher feed intake levels increase rumen concentrations of fermentation products, including VFA and hydrogen. Although hydrogen appears not to thermodynamically control methanogenesis by archaea, oxidation of NADH in rumen microorganisms, and consequently the type of VFA formed, does appear to be controlled by hydrogen partial pressure (van Lingen et al., 2016). Hence, greater feed intake levels in dairy cattle than in beef cattle may be associated with relatively (i.e., per unit of feed fermented) greater alternative hydrogen sinks for ruminal methanogenesis.

A 1-kg increase in BW from its mean $(477 \mathrm{~kg}$ ) decreased the $\mathrm{CH}_{4}$ production mitigating effect of nitrate $(P=0.041$; Table 2$)$ by $0.0183 \pm 0.00832 \%$. This reduced mitigating effect is most likely due to the relation between BW and both rumen volume and feed intake level. As explained above, increased feed intake levels may be associated with relatively (i.e., per unit of feed fermented) greater alternative hydrogen sinks for ruminal methanogenesis. The heterogeneity was greater for model II $\left(\tau^{2}=27.8\right)$ compared with model I $\left(\tau^{2}=26.3\right)$. Therefore, the final mixed-effect model for $\mathrm{CH}_{4}$ production was expressed by model I with type of cattle, nitrate dose, and DMI as explanatory variables.

\section{CONCLUSIONS}

Results from this meta-analysis indicate that nitrate supplementation reduced $\mathrm{CH}_{4}$ emissions (production in $\mathrm{g} / \mathrm{d}$ as well as yield in $\mathrm{g} / \mathrm{kg}$ of DMI) in dairy and beef cattle in a dose-dependent manner. The mitigating effect of nitrate on $\mathrm{CH}_{4}$ production and yield was greater in dairy than in beef cattle. However, effect of type of cattle appears to be related to slow-release nitrate use in beef cattle. A greater nitrate dose enhances the nitrate mitigating effect on $\mathrm{CH}_{4}$ production and yield, whereas an increased DMI reduces the mitigating effect of nitrate on $\mathrm{CH}_{4}$ production.

\section{ACKNOWLEDGMENTS}

We gratefully acknowledge financial support from the California Air Resources Board (Sacramento, CA) and USDA-National Institute of Food and Agriculture Hatch Fund (Washington, DC). The authors also acknowledge the financial support Sanne van Gastelen and André Bannink received from the Dutch Ministry of Agriculture, Nature and Food Quality (The Hague; PPS project AF-EU-18010) and the Netherlands Organisation for Scientific Research (The Hague; ALW. GAS.2) under the ERA-NET Cofund scheme ERAGAS (Cofund for Monitoring and Mitigation of Greenhouse Gases from Agri- and Silviculture) CEDERS project (Capturing Effects of Diet on Emissions from Ruminant Systems). ERA-GAS is initiated by the Joint Programming Initiative on Agriculture, Food Security and Climate Change (FACCE-JPI). The authors have not stated any conflicts of interest.

\section{REFERENCES}

Alemu, A. W., A. Romero-Perez, R. C. Araujo, and K. A. Beauchemin. 2019. Effect of encapsulated nitrate and microencapsulated blend of essential oils on growth performance and methane emissions from beef steers fed backgrounding diets. Animals (Basel) 9:21. https://doi.org/10.3390/ani9010021.

Appuhamy, J. A. D. R. N., A. B. Strathe, S. Jayasundara, C. WagnerRiddle, J. Dijkstra, J. France, and E. Kebreab. 2013. Anti-methanogenic effects of monensin in dairy and beef cattle: A metaanalysis. J. Dairy Sci. 96:5161-5173. https://doi.org/10.3168/jds .2012-5923.

Capelari, M. G. M. 2018. Investigating the potential of supplementary nitrate and monensin as dietary additives for enteric methane mitigation in ruminants. Dissertation. Department of Animal Science, Michigan State University, East Lansing.

Dijkstra, J., A. Bannink, J. France, E. Kebreab, and S. van Gastelen. 2018. Short communication: antimethanogenic effects of 3-nitrooxypropanol depend on supplementation dose, dietary fiber content, and cattle type. J. Dairy Sci. 101:9041-9047. https://doi.org/ $10.3168 /$ jds.2018-14456.

Duthie, C. A., S. M. Troy, J. J. Hyslop, D. W. Ross, R. Roehe, and J. A. Rooke. 2018. The effect of dietary addition of nitrate or increase in lipid concentrations, alone or in combination, on performance and methane emissions of beef cattle. Animal 12:280-287. https://doi.org/10.1017/S175173111700146X.

Eugène, M., D. Masse, J. Chiquette, and C. Benchaar. 2008. Metaanalysis on the effects of lipid supplementation on methane production in lactating dairy cows. Can. J. Anim. Sci. 88:331-337. https://doi.org/10.4141/CJAS07112.

Gerber, P. J., H. Steinfeld, B. Henderson, A. Mottet, C. Opio, J. Dijkman, A. Falcucci, and G. Tempio. 2013. Tackling Climate Change Through Livestock - A Global Assessment of Emissions and Mitigation Opportunities. Food and Agriculture Organization of the United Nations (FAO), Rome, Italy.

Granja-Salcedo, Y. T., R. M. Fernandes, R. C. D. Araujo, L. T. Kishi, T. T. Berchielli, F. D. D. Resende, A. Berndt, and G. R. Siqueira. 2019. Long-term encapsulated nitrate supplementation modulates rumen microbial diversity and rumen fermentation to reduce methane emission in grazing steers. Front. Microbiol. 10:614. https:/ doi.org/10.3389/fmicb.2019.00614.

Guyader, J., M. Eugène, M. Doreau, D. P. Morgavi, C. Gérard, C. Loncke, and C. Martin. 2015a. Nitrate but not tea saponin feed additives decreased enteric methane emissions in nonlactating 
cows. J. Anim. Sci. 93:5367-5377. https://doi.org/10.2527/jas $.2015-9367$.

Guyader, J., M. Eugène, B. Meunier, M. Doreau, D. P. Morgavi, M. Silberberg, Y. Rochette, C. Gerard, C. Loncke, and C. Martin. 2015b. Additive methane-mitigating effect between linseed oil and nitrate fed to cattle. J. Anim. Sci. 93:3564-3577. https://doi.org/ $10.2527 /$ jas. 2014-8196

Hedges, L. V., E. Tipton, and M. C. Johnson. 2010. Robust variance estimation in meta-regression with dependent effect size estimates. Res. Synth. Methods 1:39-65. https://doi.org/10.1002/jrsm.5.

Henry, D. 2017. Effects of bismuth subsalicylate and encapsulated calcium-ammonium nitrate on enteric methane production and apparent total-tract nutrient digestibility of beef cattle. Dissertation. Department of Animal Science, University of Florida, Gainesville.

Higgins, J. P., S. G. Thompson, J. J. Deeks, and D. G. Altman. 2003 Measuring inconsistency in meta-analyses. BMJ 327:557-560. https://doi.org/10.1136/bmj.327.7414.557.

Hristov, A. N., J. Oh, J. L. Firkins, J. Dijkstra, E. Kebreab, G. Waghorn, H. P. S. Makkar, A. T. Adesogan, W. Yang, C. Lee, P. J. Gerber, B. Henderson, and J. M. Tricarico. 2013. Mitigation of methane and nitrous oxide emissions from animal operations: I. A review of enteric methane mitigation options. J. Anim. Sci. 91:5045-5069. https://doi.org/10.2527/jas.2013-6583.

Hulshof, R. B. A., A. Berndt, W. J. J. Gerrits, J. Dijkstra, S. M. van Zijderveld, J. R. Newbold, and H. B. Perdok. 2012. Dietary nitrate supplementation reduces methane emission in beef cattle fed sugarcane-based diets. J. Anim. Sci. 90:2317-2323. https://doi .org/10.2527/jas.2011-4209.

Klop, G., B. Hatew, A. Bannink, and J. Dijkstra. 2016. Feeding nitrate and docosahexaenoic acid affects enteric methane production and milk fatty acid composition in lactating dairy cows. J. Dairy Sci. 99:1161-1172. https://doi.org/10.3168/jds.2015-10214.

Lee, C., R. C. Araujo, K. M. Koenig, and K. A. Beauchemin. 2015. Effects of encapsulated nitrate on enteric methane production and nitrogen and energy utilization in beef heifers. J. Anim. Sci. 93:2391-2404. https://doi.org/10.2527/jas.2014-8845.

Lee, C., R. C. Araujo, K. M. Koenig, and K. A. Beauchemin. 2017a. Effects of encapsulated nitrate on growth performance, nitrate toxicity, and enteric methane emissions in beef steers: Backgrounding phase. J. Anim. Sci. 95:3700-3711. https://doi.org/10.2527/jas .2017 .1460

Lee, C., R. C. Araujo, K. M. Koenig, and K. A. Beauchemin. 2017b. Effects of encapsulated nitrate on growth performance, carcass characteristics, nitrate residues in tissues, and enteric methane emissions in beef steers: Finishing phase. J. Anim. Sci. 95:37123726. https://doi.org/10.2527/jas.2017.1461.

Lee, C., and K. A. Beauchemin. 2014. A review of feeding supplementary nitrate to ruminant animals: nitrate toxicity, methane emissions, and production performance. Can. J. Anim. Sci. 94:557-570. https://doi.org/10.4141/cjas-2014-069.

Liberati, A., D. G. Altman, J. Tetzlaff, C. Mulrow, P. C. Gotzsche, J. P. Ioannidis, M. Clarke, P. J. Devereaux, J. Kleijnen, and D. Moher. 2009. The PRISMA statement for reporting systematic reviews and meta-analyses of studies that evaluate health care interventions: Explanation and elaboration. PLoS Med. 6:e1000100. https://doi.org/10.1371/journal.pmed.1000100.

Meller, R. A., B. A. Wenner, J. Ashworth, A. M. Gehman, J. Lakritz, and J. L. Firkins. 2019. Potential roles of nitrate and live yeast culture in suppressing methane emission and influencing ruminal fermentation, digestibility, and milk production in lactating Jersey cows. J. Dairy Sci. 102:6144-6156. https://doi.org/10.3168/ jds.2018-16008.

Newbold, J. R., S. M. van Zijderveld, R. B. A. Hulshof, W. B. Fokkink, R. A. Leng, P. Terencio, W. J. Powers, P. S. J. van Adrichem, N. D. Paton, and H. B. Perdok. 2014. The effect of incremental levels of dietary nitrate on methane emissions in Holstein steers and performance in Nelore bulls. J. Anim. Sci. 92:5032-5040. https:// doi.org/10.2527/jas.2014-7677.

Niu, M., E. Kebreab, A. N. Hristov, J. Oh, C. Arndt, A. Bannink, A. R. Bayat, A. F. Brito, T. Boland, D. Casper, L. A. Crompton, J. Dijkstra, M. A. Eugène, P. C. Garnsworthy, M. N. Haque, A.
L. F. Hellwing, P. Huhtanen, M. Kreuzer, B. Kuhla, P. Lund, J. Madsen, C. Martin, S. C. McClelland, M. McGee, P. J. Moate, S. Muetzel, C. Muñoz, P. O'Kiely, N. Peiren, C. K. Reynolds, A. Schwarm, K. J. Shingfield, T. M. Storlien, M. R. Weisbjerg, D. R. Yáñez-Ruiz, and Z. Yu. 2018. Prediction of enteric methane production, yield and intensity in dairy cattle using an intercontinental database. Glob. Change Biol. 24:3368-3389. https://doi .org/10.1111/gcb.14094.

Olijhoek, D. W., A. L. F. Hellwing, M. Brask, M. R. Weisbjerg, O. Hojberg, M. K. Larsen, J. Dijkstra, E. J. Erlandsen, and P. Lund 2016. Effect of dietary nitrate level on enteric methane production, hydrogen emission, rumen fermentation, and nutrient digestibility in dairy cows. J. Dairy Sci. 99:6191-6205. https://doi.org/10 .3168/jds.2015-10691.

Rebelo, L. R., I. C. Luna, J. D. Messana, R. C. Araujo, T. A. Simioni, Y. T. Granja-Salcedo, E. S. Vito, C. Lee, I. A. Teixeira, J. A. Rooke, and T. T. Berchielli. 2019. Effect of replacing soybean meal with urea or encapsulated nitrate with or without elemental sulfur on nitrogen digestion and methane emissions in feedlot cattle. Anim. Feed Sci. Technol. 257:114293. https://doi.org/10.1016/j .anifeedsci.2019.114293.

Sar, C., B. Santoso, Y. Gamo, T. Kobayashi, S. Shiozaki, K. Kimura, H. Mizukoshi, I. Arai, and J. Takahashi. 2004. Effects of combination of nitrate with beta 1-4 galacto-oligosaccharides and yeast (Candida kefyr) on methane emission from sheep. Asian-Australas. J. Anim. Sci. 17:73-79. https://doi.org/10.5713/ajas.2004.73.

Schwarzer, G., J. R. Carpenter, and G. Rücker. 2015. Meta-analysis with R. Springer International Publishing Switzerland. Springer Cham Heidelberg, New York, NY. https://doi.org/10.1007/978-3 -319-21416-0.

Smith, P., M. Bustamante, H. Ahammad, H. Clark, H. M. Dong, E. A. Elsiddig, H. Haberl, R. Harper, J. House, and M. Jafari. 2014. Agriculture, Forestry and Other Land Use (AFOLU). In Climate Change 2014: Mitigation of Climate Change. Contribution of Working Group III to the Fifth Assessment Report of the Intergovernmental Panel on Climate Change. Cambridge University Press, Cambridge, UK, and New York, NY.

Tanner-Smith, E. E., E. Tipton, and J. R. Polanin. 2016. Handling complex meta-analytic data structures using robust variance estimates: A tutorial in R. J. Dev. Life Course Criminol. 2:85-112. https://doi.org/10.1007/s40865-016-0026-5.

Tipton, E. 2015. Small sample adjustments for robust variance estimation with meta-regression. Psychol. Methods 20:375-393. https:// doi.org/10.1037/met0000011

Tomkins, N., A. J. Parker, G. Hepworth, and M. J. Callaghan. 2018. Nitrate supplementation has marginal effects on enteric methane production from Bos indicus steers fed Flinders grass (Iseilema spp.) hay, but elevates blood methaemoglobin concentrations. Anim. Prod. Sci. 58:262-270. https://doi.org/10.1071/AN16002.

Troy, S. M., C. A. Duthie, J. J. Hyslop, R. Roehe, D. W. Ross, R. J. Wallace, A. Waterhouse, and J. A. Rooke. 2015. Effectiveness of nitrate addition and increased oil content as methane mitigation strategies for beef cattle fed two contrasting basal diets. J. Anim. Sci. 93:1815-1823. https://doi.org/10.2527/jas.2014-8688.

Ungerfeld, E. M., and R. A. Kohn. 2006. The role of thermodynamics in the control of ruminal fermentation. Pages 55-85 in Ruminant Physiology: Digestion, Metabolism and Impact of Nutrition on Gene Expression, Immunology and Stress. K. Sejrsen, T. Hvelplund, and M. O. Nielsen, ed. Wageningen Academic Publishers, Wageningen, the Netherlands.

Upton, G., and I. Cook. 1996. Understanding Statistics. Oxford University Press, Oxford, UK.

van Gastelen, S., J. Dijkstra, and A. Bannink. 2019. Are dietary strategies to mitigate enteric methane emission equally effective across dairy cattle, beef cattle, and sheep? J. Dairy Sci. 102:6109-6130. https://doi.org/10.3168/jds.2018-15785.

van Lingen, H. J., C. M. Plugge, J. G. Fadel, E. Kebreab, A. Bannink, and J. Dijkstra. 2016. Thermodynamic driving force of hydrogen on rumen microbial metabolism: A theoretical investigation. PLoS One 11:e0161362. https://doi.org/10.1371/journal.pone.0161362. 
van Wyngaard, J. D. V., R. Meeske, and L. J. Erasmus. 2018. Effect of dietary nitrate on enteric methane emissions, production performance and rumen fermentation of dairy cows grazing kikuyu-dominant pasture during summer. Anim. Feed Sci. Technol. 244:76-87. https://doi.org/10.1016/j.anifeedsci.2018.08.005.

van Wyngaard, J. D. V., R. Meeske, and L. J. Erasmus. 2019. Effect of dietary nitrate on enteric methane emissions, production performance and rumen fermentation of dairy cows grazing ryegrass pasture during spring. Anim. Feed Sci. Technol. 252:64-73. https: //doi.org/10.1016/j.anifeedsci.2019.04.006.

van Zijderveld, S. M., B. Fonken, J. Dijkstra, W. J. J. Gerrits, H. B. Perdok, W. Fokkink, and J. R. Newbold. 2011a. Effects of a combination of feed additives on methane production, diet digestibility, and animal performance in lactating dairy cows. J. Dairy Sci. 94:1445-1454. https://doi.org/10.3168/jds.2010-3635.

van Zijderveld, S. M., W. J. J. Gerrits, J. A. Apajalahti, J. R. Newbold, J. Dijkstra, R. A. Leng, and H. B. Perdok. 2010. Nitrate and sulfate: Effective alternative hydrogen sinks for mitigation of ruminal methane production in sheep. J. Dairy Sci. 93:5856-5866. https://doi.org/10.3168/jds.2010-3281.

van Zijderveld, S. M., W. J. J. Gerrits, J. Dijkstra, J. R. Newbold, R. B. A. Hulshof, and H. B. Perdok. 2011b. Persistency of methane mitigation by dietary nitrate supplementation in dairy cows. J. Dairy Sci. 94:4028-4038. https://doi.org/10.3168/jds.2011-4236.

Veneman, J. B., S. Muetzel, K. J. Hart, C. L. Faulkner, J. M. Moorby, H. B. Perdok, and C. J. Newbold. 2015. Does dietary mitigation of enteric methane production affect rumen function and animal productivity in dairy cows? PLoS One 10:e0140282. https://doi .org/10.1371/journal.pone.0140282.
Viechtbauer, W. 2010. Conducting meta-analyses in R with the metafor package. J. Stat. Softw. 36:1-48. https://doi.org/10.18637/jss .v036.i03.

Villar, M. L., R. S. Hegarty, J. V. Nolan, I. R. Godwin, and M. McPhee. 2020. The effect of dietary nitrate and canola oil alone or in combination on fermentation, digesta kinetics and methane emissions from cattle. Anim. Feed Sci. Technol. 259:114294. https: //doi.org/10.1016/j.anifeedsci.2019.114294.

Wang, R., M. Wang, E. M. Ungerfeld, X. M. Zhang, D. L. Long, H. X. Mao, J. P. Deng, A. Bannink, and Z. L. Tan. 2018. Nitrate improves ammonia incorporation into rumen microbial protein in lactating dairy cows fed a low-protein diet. J. Dairy Sci. 101:9789 9799. https://doi.org/10.3168/jds.2018-14904.

Zhang, X., R. F. Medrano, M. Wang, K. A. Beauchemin, Z. Y. Ma, R. Wang, J. N. Wen, L. A. Bernard, and Z. L. Tan. 2019. Effects of urea plus nitrate pretreated rice straw and corn oil supplementation on fiber digestibility, nitrogen balance, rumen fermentation, microbiota and methane emissions in goats. J. Anim. Sci. Biotechnol. 10:6. https://doi.org/10.1186/s40104-019-0312-2.

\section{ORCIDS}

X. Y. Feng (ํ) https://orcid.org/0000-0003-4317-6738

J. Dijkstra ๑ https://orcid.org/0000-0003-3728-6885

S. van Gastelen ำ https://orcid.org/0000-0003-4547-8449

J. France @ https://orcid.org/0000-0003-2923-7098

E. Kebreab @ https://orcid.org/0000-0002-0833-1352 